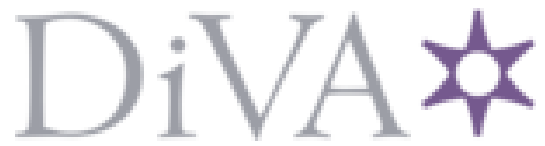

http://www.diva-portal.org

Preprint

This is the submitted version of a paper published in Carbon.

Citation for the original published paper (version of record):

Korobov, M V., Talyzin, A V., Rebrikova, A T., Shilayeva, E A., Avramenko, N V. et al. (2016)

Sorption of polar organic solvents and water by graphite oxide: thermodynamic approach

Carbon, 102: 297-303

https://doi.org/10.1016/j.carbon.2016.02.070

Access to the published version may require subscription.

N.B. When citing this work, cite the original published paper.

Permanent link to this version:

http://urn.kb.se/resolve?urn=urn:nbn:se:umu:diva-119625 


\section{Sorption of Polar Organic solvents and Water by Graphite oxide:}

\section{Thermodynamic Approach.}

Mikail V. Korobov ${ }^{1, *}$, Aleksandr V. Talyzin ${ }^{2}$, Anastasiya T. Rebrikova ${ }^{1}$, Elizaveta A. Shilayeva ${ }^{1}$, Natalya V. Avramenko ${ }^{1}$, Alexander N. Gagarin ${ }^{1}$, Nikolay B. Ferapontov ${ }^{1}$

${ }^{1}$ Department of Chemistry, Moscow State University, Leninskie Gory 1-3, Moscow 119991, Russia

${ }^{2}$ Umeå University, Department of Physics, S-90187 Umeå, Sweden

ABSTRACT: Sorption of polar organic solvents $\mathrm{CH}_{3} \mathrm{OH}, \mathrm{C}_{4} \mathrm{H}_{8} \mathrm{O}$ (THF), $\mathrm{CH}_{3} \mathrm{CN}, \mathrm{C}_{3} \mathrm{H}_{7} \mathrm{NO}$ (DMF), $\mathrm{C}_{2} \mathrm{H}_{6} \mathrm{OS}$ (DMSO), $\mathrm{C}_{5} \mathrm{H}_{9} \mathrm{NO}$ (NMP) and water was quantitatively evaluated for Hummers (H-GO) and Brodie (B-GO) graphite oxides at $\mathrm{T}=298 \mathrm{~K}$ and at melting temperature ( $\mathrm{Tm}$ ) of the solvents. H-GO showed stronger sorption compared to B-GO for all studied solvents and the increase of sorption upon lowering temperature was observed for both H-GO and B-GO. Thermodynamic equations allowed to explain earlier reported "maximums" of swelling/sorption in the binary systems $\mathrm{H}-\mathrm{GO}$ - solvent at $\mathrm{Tm}$. The specific relation between the values of enthalpies of sorption and melting leads to the change of sign in enthalpies of sorption at $\mathrm{Tm}$ and causes maximal swelling/sorption. The same thermodynamic explanation was given for the "maximum" on the swelling vs. pressure dependence in B-GO and $\mathrm{H}-\mathrm{GO}-\mathrm{H}_{2} \mathrm{O}$ systems earlier reported at pressure of phase transition "liquid water-ice VI". Notably higher sorption of $\mathrm{H}_{2} \mathrm{O}$ was observed for $\mathrm{H}-\mathrm{GO}$ compared to $\mathrm{H}-\mathrm{GO}$ membrane (H-GOm) at high relative humidity $(\mathrm{RH})$, $\mathrm{RH}>0$,75. Experimental sorption isotherm of H-GOm was used to simulate permeation rates of water through $\mathrm{H}-\mathrm{GOm}$ and to estimate effective diffusion coefficient of water through the membrane.

* Corresponding author. E-mail: mkorobov49@gmail.com (Mikhail V.Korobov). 


\section{Introduction}

Graphite oxide (GO) is non-stoichiometric derivative of graphite which attracted wide attention recently as a precursor for preparation of various graphene based materials [1,2]. Contrary to graphite, GO is typically hydrophilic, dispersible in polar solvents and easily sorbs polar solvents into inter-layer space inducing the increase of the inter-layer distance (swelling) [3]. Simple sonication in polar solvents leads to exfoliation of GO with formation of graphene oxide $[4,5]$ which can be then reduced to graphene or to chemically modified graphene [4-7]. Very strong interest was recently attracted to multilayered GO materials obtained by deposition of graphene oxide sheets using water and polar solvent solutions: thin films [8,9], papers [10], and membranes [11-18]. In particular, graphene oxide membranes were suggested for nanofiltration $[14,15]$, separation of vapor and liquid mixtures $[13,16]$. Very thin graphene oxide films (2-3 layer thick) were also demonstrated to be highly selective in separation of gas mixtures, whereas the properties of the membranes can be controlled using variations of humidity $[12,17]$.

Sorption of water and organic solvents by different GO samples was evaluated in a number of studies [19-23]. As revealed by XRD the inter-layer distance in GO at ambient temperature increases with the increase of humidity [19]. H-GO in the excess of $\mathrm{CH}_{3} \mathrm{OH}, \mathrm{C}_{2} \mathrm{H}_{5} \mathrm{OH}$ and $\mathrm{H}_{2} \mathrm{O}$ shows gradual changes of interlayer distance upon both temperature [24] and pressure variations [25] with maximums at the points of solvent freezing/melting. However, such anomalous behavior is poorly understood and lack theoretical explanation. For B-GO the abrupt changes of the inter-layer distance were observed in the systems with $\mathrm{CH}_{3} \mathrm{OH}, \mathrm{C}_{2} \mathrm{H}_{5} \mathrm{OH}, \mathrm{DMF}$ and $\mathrm{CH}_{3} \mathrm{CN}$, suggesting transitions between two solvate phase to occur upon temperature variations [26, 27]. In the present study the intercalation of GO with water and typical polar organic solvents was quantitatively characterized and described theoretically using general thermodynamic approach. The values of sorption were measured for several common polar solvents at melting temperature 
of the solvent and at ambient temperature. The water sorption isotherms were obtained at ambient temperature for Hummers $\mathrm{H}-\mathrm{GO}$ and for $\mathrm{H}-\mathrm{GOm}$ membrane prepared from $\mathrm{H}-\mathrm{GO}$ powder. Simple thermodynamic model allows to give interpretation of sorption data along with the XRD values for interlayer distances in swelled GO and to explain the peculiar temperature/pressure dependence of sorption and swelling.

\section{Experimental}

\subsection{Materials}

H-GO was purchased from ACS Material. B-GO samples were provided by Dr. T. Szabo and the synthetic procedure was described elsewhere [28]. The comparative description of both these samples was given in ref. [29]. The samples were dried to a constant mass under vacuum $\left(10^{-4}\right.$ bar, 12 hours) and/or in the desiccators with $\mathrm{P}_{2} \mathrm{O}_{5}$ for 3-5 days. The $\mathrm{C} / \mathrm{O}$ ratio as measured by XPS after drying was 2.47 and 2.85, for H-GO and B-GO, respectively [29]. The H-GOm membranes were prepared using vacuum driven filtration, details are available in ref. [30]. Organic solvents were specially re-distilled before use. The resulting purity was $>99 \%$ according to DSC. Mili-Q water was used for measurements.

\subsection{Methods}

Sorption measurements at $\mathrm{T}=298 \pm 1 \mathrm{~K}$ were performed by isopiestic (ISP) method. Equilibration of $\mathrm{GO}$ with $\mathrm{H}_{2} \mathrm{O}$ and organic solvents vapors persisted until the mass of $\mathrm{GO}$ saturated with water became constant (5-10 days). Amount of sorbed solvent was also evaluated at the temperature point of solvent melting using DSC heating traces. For this experiments GO powder samples are mixed with certain excess of solvent. The amount of bulk solvent decreases due to the intercalation of some solvent into the GO structure; the sorbed solvent does not contribute to the measured melting enthalpy (see Supplimentary Material for details). The amount of solvent sorbed by the GO structure can be calculated using the known enthalpy of solvent melting and measured decrease in melting enthalpy for given amounts of powder and solvent. 
DSC-30 TA from Mettler was used for measurements. The quantitative measurements rely on heating traces with the scanning rate $5 \mathrm{~K} / \mathrm{min}$.

Water sorption isotherms for H-GO and H-GOm were obtained by ISP and for H-GO additionally by dynamic desorption method. To provide necessary level of relative humidity $(\mathrm{RH})$ in ISP the aqueous saturated solutions of the following salts were used: $\mathrm{LiCl}(\mathrm{RH}=0.11)$, $\mathrm{MgCl}_{2}(\mathrm{RH}=0.33), \mathrm{NaBr}(\mathrm{RH}=0.57), \mathrm{NaCl}(\mathrm{RH}=0.75), \mathrm{KNO}_{3}(\mathrm{RH}=0.93), \mathrm{K}_{2} \mathrm{SO}_{4}(\mathrm{RH}=0.97)$. Typical mass of dry H-GO, B-GO and H-GOm in ISP were 10-15 and $2 \mathrm{mg}$, respectively. Dynamic desorption measurements (DDM) were performed on the instrument described in ref. [31]. In the experiment the rate of continuous desorption of water under equilibrium conditions was measured. The relative equilibrium pressures of water were calculated from the rates of desorption using the "film model" [32]. The basics of the method are given in ref.[33] and in the Supplementary materials. The samples studied were $\sim 130-135 \mathrm{mg}$ of dry H-GO mixed with the excess of water $(1 \mathrm{~g})$. To sustain equilibrium conditions typical desorption experiment lasted for 10 days.

\section{Results and Discussion}

\subsection{Sorption of organic solvents and water}

Summary of sorption experiments is given in Table 1 for several common polar solvents. The amount of sorbed solvents is typically provided in weight, volume (Table 1) and in molar proportion (see Fig.1) relative to the amount of powder. First of all, H-GO and B-GO showed remarkably different sorption properties with $\mathrm{H}-\mathrm{GO}$ showing higher sorption at ambient temperature for all of studied solvents. It is also general trend that the sorption increases with the decrease of temperature from the ambient down to the melting temperature of the solvent. This was observed for both H-GO and B-GO and for all of the solvents studied. The only exception is sorption of acetonitrile at low temperatures, however for this solvent the deviation is explained 
by complete delamination of $\mathrm{H}-\mathrm{GO}$ structure at low temperatures [27]. When melting temperature of solvents was close to ambient $\left(\mathrm{H}_{2} \mathrm{O}, \mathrm{DMSO}\right)$, the values of sorption measured by two different methods (ISP and DSC) were almost equal. At least for $\mathrm{H}_{2} \mathrm{O}$ and DMSO no additional sorption (no Schreder effect!) was found for the samples in direct contact with liquid solvent (DSC) compared to samples equilibrated with the saturated vapors of the same solvent (ISP).

\subsection{Formation of layers}

The data presented in the Table 1 provide interesting insights into the nature of the inter-layer swelling of graphite oxides. For B-GO the volumetric sorption at ambient temperature $\left(\mathrm{cm}^{3} / \mathrm{g}\right)$ is almost equal for all of the solvents studied. Figure 1a shows sorption of studied solvents by BGO expressed both in molar and volumetric units. Remarkably, the molar fraction of sorbed solvents is almost the same for several solvents except $\mathrm{H}_{2} \mathrm{O}$ and $\mathrm{CH}_{3} \mathrm{OH}$. However, the trend becomes almost uniform if the sorption is expressed in volumetric units. The average volume sorption for nine solvents in Fig. $1 \mathrm{a}$ is $0,39 \pm 0,05 \mathrm{~cm}^{3} / \mathrm{g}$ compared to $0,0073 \pm 0,0044$ and $0,39 \pm 0,10$ for sorption measured in $\mathrm{mol} / \mathrm{g}$ and $\mathrm{g} / \mathrm{g}$, respectively. These data can be interpreted as following: polar solvents at ambient temperature occupy the same volume in the inter-plane space of B-GO and stoichiometry of sorption sensitive to molar proportion $(\mathrm{mol} / \mathrm{g})$ is a less important factor.

Table 1. Sorption of polar solvents by H-GO, B-GO and H-GOm.

\begin{tabular}{|c|c|c|c|c|}
\hline \multirow{4}{*}{ Solvent } & \multicolumn{2}{|c|}{ H-GO } & \multicolumn{2}{c|}{ B-GO } \\
\cline { 2 - 5 } & $\mathrm{DSC}$, & Isopiestic, & DSC, & Isopiestic, \\
& $\mathrm{g} / \mathrm{g}^{\mathrm{a}}$ & $\mathrm{g} / \mathrm{g}$ & $\mathrm{g} / \mathrm{g}$ & $\mathrm{g} / \mathrm{g}$ \\
& $\left(\mathrm{cm}^{3} / \mathrm{g}\right)^{\mathrm{b}}$ & $\left(\mathrm{cm}^{3} / \mathrm{g}\right)$ & $\left(\mathrm{cm}^{3} / \mathrm{g}\right)$ & $\left(\mathrm{cm}^{3} / \mathrm{g}\right)$ \\
& $\mathrm{Tm}^{\mathrm{c}}$ & $\mathrm{T}=298 \mathrm{~K}$ & $\mathrm{Tm}$ & $\mathrm{T}=298 \mathrm{~K}$ \\
\hline $1 . \mathrm{CH}_{3} \mathrm{CN}$ & $0,48 \pm 0,03^{\mathrm{d}}$ & $0,34 \pm 0,01$ & $0,53 \pm 0,04$ & $0,25 \pm 0,02$ \\
\hline
\end{tabular}




\begin{tabular}{|c|c|c|c|c|}
\hline $\mathrm{Tm}=229,3$ & $(0,62)$ & $(0,44)$ & $(0,68)$ & $(0,32)$ \\
\hline 2. THF & $1,06 \pm 0,04$ & $0,78 \pm 0,01$ & $0,64 \pm 0,05$ & $0,35 \pm 0,01$ \\
\hline $\mathrm{Tm}=164,6$ & $(1,23)$ & $(0,88)$ & $(0,72)$ & $(0,40)$ \\
\hline $\begin{array}{l}\text { 3. } \mathrm{CH}_{3} \mathrm{OH} \\
\mathrm{Tm}=175.3\end{array}$ & $0,95 \pm 0,05$ & $\begin{array}{c}0,48 \pm 0,02 \\
(0.61)\end{array}$ & $\begin{array}{c}0,55 \pm 0,04[34] \\
(0.69)\end{array}$ & $\begin{array}{c}0,31 \pm 0,07 \\
0.31[22] \\
(0.40)\end{array}$ \\
\hline 4. DMF & $0,93 \pm 0,03$ & $0,63 \pm 0,01$ & $0,74 \pm 0,03$ & $0,41 \pm 0,05$ \\
\hline $\mathrm{Tm}=212,8$ & $(0,93)$ & $(0,67)$ & $(0,78)$ & $(0,43)$ \\
\hline 5. NMP & $1,18 \pm 0,12$ & $0,55 \pm 0,01$ & $0,90 \pm 0,12$ & $0,44 \pm 0,01$ \\
\hline $\mathrm{Tm}=248,4$ & $(1,14)$ & $(0,53)$ & $(0,87)$ & $(0,43)$ \\
\hline 6. DMSO & $0,83 \pm 0,03$ & $0,78 \pm 0,01$ & $0,49 \pm 0,08$ & $0,42 \pm 0,01$ \\
\hline $\mathrm{Tm}=291,7$ & $(0,76)$ & $(0,71)$ & $(0,45)$ & $(0,38)$ \\
\hline 7. $\mathrm{H}_{2} \mathrm{O}$ & $0,79 \pm 0,04$ & $0,75 \pm 0,02$ & $0,33 \pm 0,04$ & $0,33 \pm 0,02$ \\
\hline $\mathrm{Tm}=273$ & $(0.79)$ & $(0.75)$ & $(0.33)$ & $(0.33)$ \\
\hline \multicolumn{5}{|c|}{ H-GOm } \\
\hline 1. $\mathrm{H}_{2} \mathrm{O}$ & $0,52 \pm 0,03$ & $0,49 \pm 0,03$ & & \\
\hline $\mathrm{Tm}=273$ & $(0,52)$ & $(0,49)$ & & \\
\hline
\end{tabular}

${ }^{\mathrm{a}}(\mathrm{g} / \mathrm{g})$ - grams of the solvent per gram of $\mathrm{GO} ;{ }^{\mathrm{b}}\left(\mathrm{cm}^{3} / \mathrm{g}\right)-\mathrm{cm}^{3}$ of the solvent per gram of GO, densities of the solvents are taken from ref. [35]; ${ }^{\mathrm{c}} \mathrm{Tm}$ - melting temperature of the solvent [35]. Sorptions, measured by DSC, referred to Tm; ${ }^{\mathrm{d}}$ Exclusively low sorption of $\mathrm{CH}_{3} \mathrm{CN}$ by $\mathrm{H}-\mathrm{GO}$ at Tm is caused by delamination of $\mathrm{H}-\mathrm{GO}$ [27].

Polar solvents form a "volume layer" between two B-GO planes though this layer is not necessarily regular one-molecule thick. The average volume of the layer is close to $0,45 \mathrm{~cm}^{3} / \mathrm{g}$, the number was earlier suggested as geometric limit of stability of B-GO upon intercalation [22]. However at melting temperatures of the solvents this volume was almost doubled and averaged 
$0,75 \pm 0,08 \mathrm{~cm}^{3} / \mathrm{g}$ (solvents $1-5$ in Table 1 ) suggesting formation of "two layers" between every two GO planes. For B-GO intercalated with $\mathrm{CH}_{3} \mathrm{CN}, \mathrm{CH}_{3} \mathrm{OH}$ and DMF the first order phase transition was observed below the ambient temperature with the release of $\sim 0,33 \mathrm{~cm}^{3} / \mathrm{g}$ of the solvent and the abrupt decrease of the inter-layer distance on heating [26,27]. This transition detected by XRD and DSC may be considered as incongruent melting of swelled B-GO with two volume layers resulting in formation of B-GO with one volume layer of solvent molecules in the inter-plane space.

The same tendencies are less pronounced for sorption of solvents by H-GO, (see Fig. 1b). Once again, molar sorption of water strongly deviates from other solvents. For H-GO the averaged values for volume/molar sorption are $0,66 \pm 0,15 \mathrm{~cm}^{3} / \mathrm{g}$ and $0,014 \pm 0,012 \mathrm{~mol} / \mathrm{g}$ (solvents $1-7$ in Table 1) and 1,03 $\pm 0,26 \mathrm{~cm}^{3} / \mathrm{g}$ and 0,016 $\pm 0,012$ (solvents 1-5 in Table 1) for ambient temperature and melting temperature of the solvent, respectively. DSC traces didn't show any peaks corresponding to incongruent melting in the systems H-GO-solvent from Table 1. The gradual decrease of the inter-plane distances above the melting point on heating was observed by XRD in H-GO saturated with $\mathrm{CH}_{3} \mathrm{OH}, \mathrm{C}_{2} \mathrm{H}_{5} \mathrm{OH}$ and $\mathrm{CH}_{3} \mathrm{CN}[27,36]$. No abrupt changes were detected. The concept of "layers" thus doesn't look useful for the intercalation of polar solvents into HGO. 


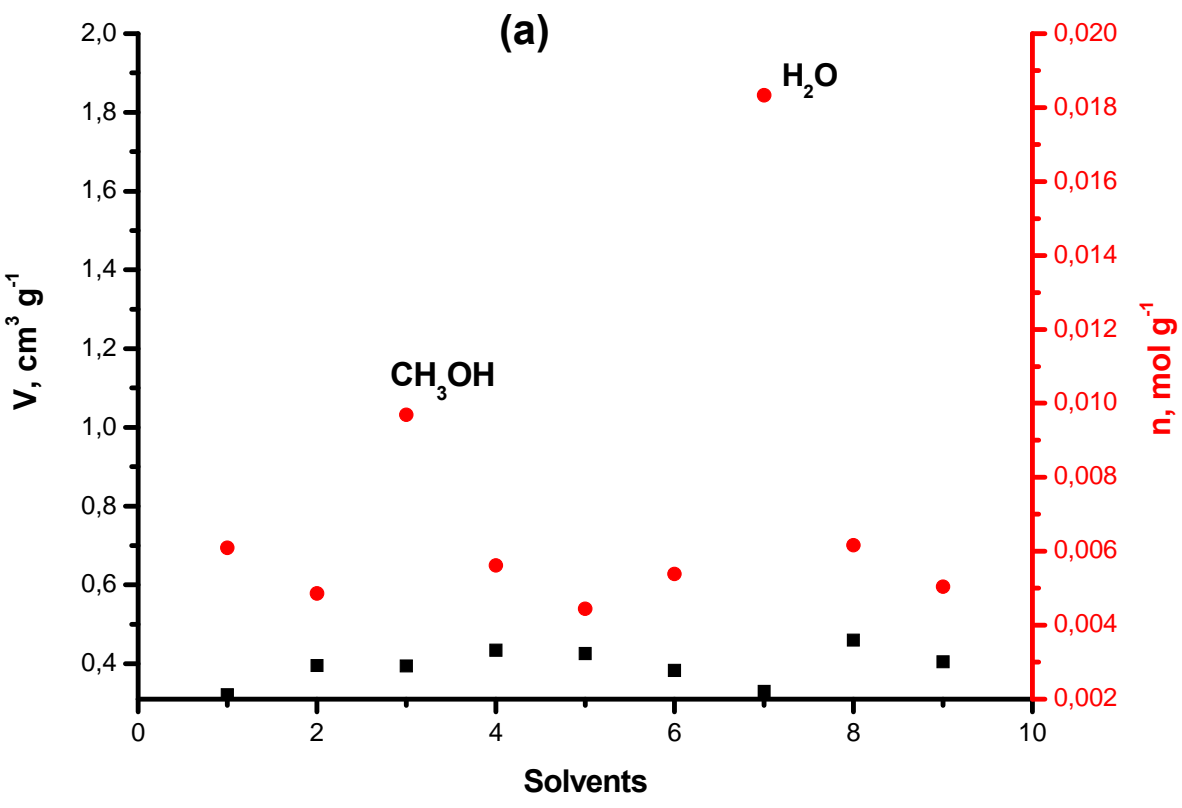

(b)

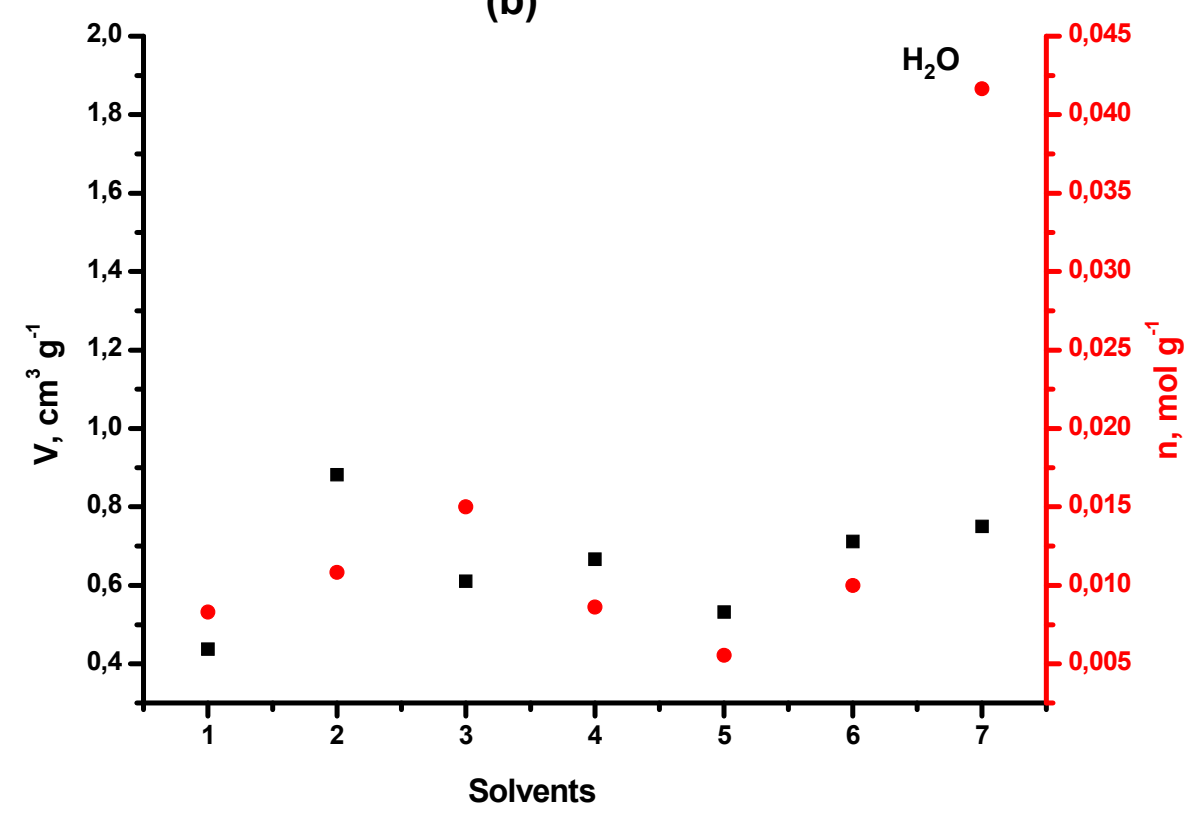

Fig.1 Volume sorption (black squares) and molar sorption (red circles) at $\mathrm{T}=298 \mathrm{~K}$.

(a) For 9 polar solvents in B-GO. Numbers 1-7 plotted as abscissas referred to the solvents in Table 1, $8-\mathrm{C}_{3} \mathrm{H}_{7} \mathrm{OH}, 9-\mathrm{CHCl}_{3}$. Data for 8,9 are taken from ref. [22].

(b) For 7 polar solvents in H-GO. Numbers 1-7 plotted as abscissas referred to the solvents in Table 1. 


\subsection{Thermodynamic model to describe temperature/pressure dependence of sorption by $H$-GO}

and $B-G O$

As it can be seen from the Table 1 the solvent sorption by H-GO decreases with the increase of temperature from the melting point of the solvent to ambient temperature. The same tendency was earlier observed by XRD for the inter-plane distances, d, in $\mathrm{H}-\mathrm{GO}$ swelled in $\mathrm{H}_{2} \mathrm{O}, \mathrm{CH}_{3} \mathrm{OH}$, $\mathrm{C}_{2} \mathrm{H}_{5} \mathrm{OH}$ and $\mathrm{CH}_{3} \mathrm{CN}$, also for $\mathrm{B}-\mathrm{GO}$ in $\mathrm{H}_{2} \mathrm{O}[24,27,36]$. In these systems the inter-plane distance changed gradually with temperature and reached maximum at melting temperatures of the solvents (see Fig.2).

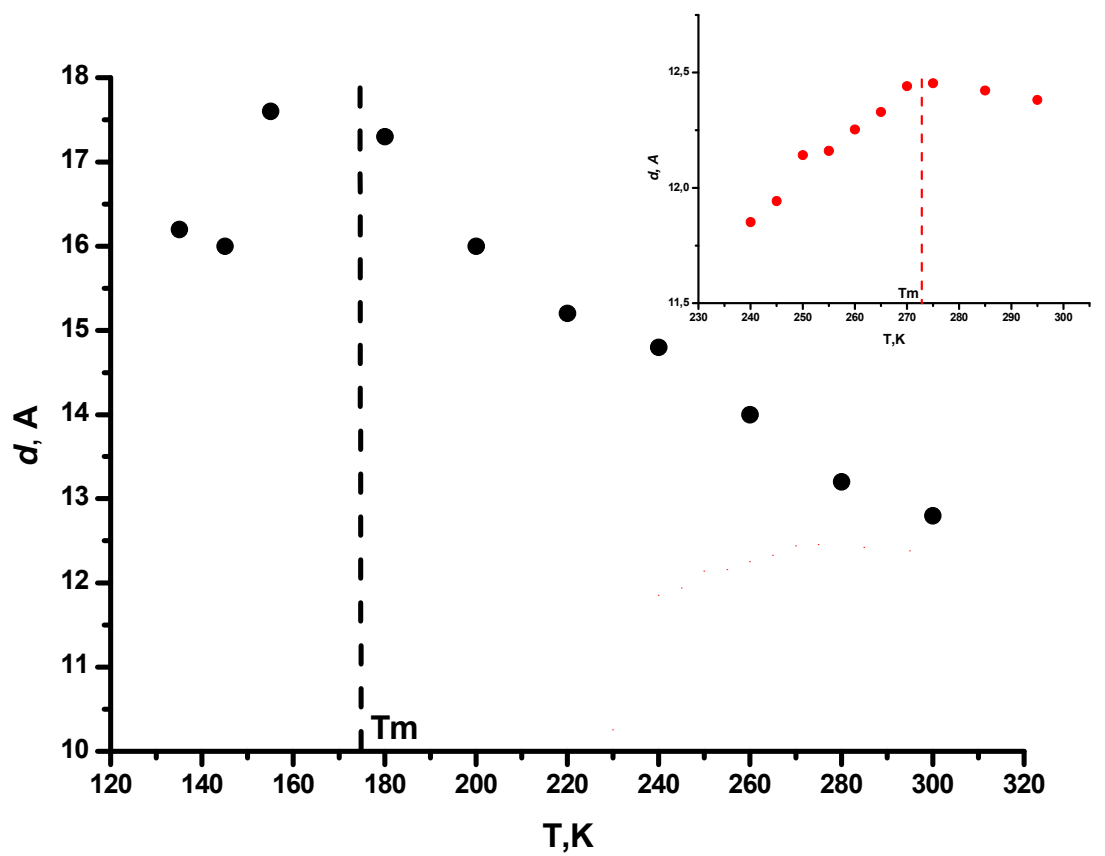

Fig. 2. Temperature dependences of the inter-plane distance d (001) in the system H-GO -

$\mathrm{CH}_{3} \mathrm{OH}$ on heating. The data are taken from ref. [36]. Inset: the same dependence in the system $\mathrm{H}-\mathrm{GO}-\mathrm{H}_{2} \mathrm{O}[24]$

The nature of this peculiar temperature dependence remained unclear to the moment. Here we propose simple model which explains available data using thermodynamic approach.

First, we assume the swelled $\mathrm{H}-\mathrm{GO}$ (and $\mathrm{B}-\mathrm{GO}$ in $\mathrm{H}_{2} \mathrm{O}$ ) to be an equilibrium bulk phase, namely a "solid solution of the solvent in GO"(see Supplementary Material for discussion). The 
equilibrium of swelled GO with the free solvent at temperatures below the melting point of the solvent and constant pressure is described then by

$\mu_{S}^{G O}(T, x)=\mu_{S}^{0}(T)$

where $\mu_{S}^{G O}(T, x), \mu_{S}^{0}(T)$ are chemical potentials of the solvent at temperature $\mathrm{T}$ in GO at saturation ( $\mathrm{x}$ is a mass fraction of the solvent at saturation) and in solid solvent, respectively. After routine transformation one gets (see Supplementary Material)

$$
\frac{\left(H_{S}^{G O}(T, x)-H_{S}^{0, s}(T)\right)}{\left(\frac{\partial \mu_{S}^{G O}}{\partial x}\right)_{T}}=\left(\frac{d x}{d T}\right)
$$

where $H_{S}^{G O}(T, x), H_{S}^{0, s}(T)$ are partial molar enthalpies of the solvent in saturated swelled GO and in the solid solvent at temperature T, respectively, and $H_{S}^{G O}(T, x)-H_{S}^{0, s}(T)$ is partial enthalpy of sorption at saturation at temperature T.

The derivative in the right hand side determines temperature dependence of sorption at saturation, $\mathrm{x}$, and hence the dependence of $\mathrm{d}$ over temperature; $\mathrm{x}$ changes gradually with the temperature. The sign of the derivative is governed by the sign of the partial enthalpy of sorption in the numerator in the left hand side of the equation, the denominator being always positive. $\left(\frac{\partial \mu_{S}^{G O}}{\partial x}\right)_{T}>0$ is a condition for stability of swelled GO. The derivative may change sign at the melting temperature of the solvent (singular point!) on heating due to the change of the phase in equilibrium with the swelled GO. In the left hand side of eq.(1) partial enthalpy of sorption of the solvent from the solid solvent is replaced at the melting point by the same sorption enthalpy $H_{S}^{G O}(T, x)-H_{S}^{0, l}(T)$ from the liquid solvent. The difference between two sorption enthalpies is equal to the enthalpy of melting of the solvent, $\Delta H_{m, S}^{0}$. Assuming the sorption enthalpy to be negative for the liquid solvents (see Table 1, 
decrease of sorption above the melting point!), the sorption enthalpy from the solid solvents will be positive if

$$
/ H_{S}^{G O}-H_{S}^{0, l} /<\Delta H_{m, S}^{0}
$$

If this condition is met maximums of the inter-plane distance and sorption will appear at the melting point of the solvent. Estimations, based on the results given in Table 1 (see Supplementary Material, Table 2S) show that this is the case.

Equations (1) and (2) present reasonable explanation for "temperature dependent structural breathing" previously observed for H-GO swelled in a number of polar solvents and for B-GO swelled in water. "Maximums" (actually, singular points) of d(001) in all these systems were observed at the melting points of corresponding solvents i.e. in the points where solid phase of the solvent on heating is replaced by liquid phase. Equation (1) is a routine thermodynamic relation. The peculiar dependence of the swelling vs. temperature (characterized by presence of maximum) in the systems GO-polar solvent can be derived from the fact that absolute values of enthalpies of sorption are smaller than corresponding melting enthalpies of the solvents (see inequality (2)).

Based on the results presented in Table 1 and in Table 2S (see Supplementary Material) the nonmonotonous gradual type of temperature dependence of d (with maximum!) is expected for $\mathrm{H}$ GO swelled in THF, NMP, DMF and DMSO and for B-GO swelled in THF, NMP, DMSO. As it was mentioned above, for B-GO in $\mathrm{CH}_{3} \mathrm{CN}, \mathrm{CH}_{3} \mathrm{OH}$ and DMF instead of the gradual change of $\mathrm{d}(001)$ the abrupt decrease of inter-plane distance is found at specific temperature (different for different solvents) in between the melting point of the solvent and ambient temperature. In this case the swelled B-GO has to be considered as "solid solvate with the temperature independent composition" rather than "solid solution with variable composition" as in case of H-GO. The difference between "gradual" and "abrupt" temperature dependence is evident. It is worth noting however that these two types of dependence may be considered as two extreme cases of one and the same phenomena, namely, of incongruent melting of solid solvates 
of GO with narrow or wide homogeneity ranges, respectively. The DSC peaks corresponding to the "incongruent melting of the B-GO solvates" were wider than the peaks of melting of the free solvents (typical first order phase transitions) in the same DSC traces [26,27]. "Solid solvates" of B-GO definitely are not point compounds and have certain homogeneity ranges. Further expansion of the homogeneity range will lead to the disappearance of the DSC peaks and to the gradual change of $\mathrm{d}(001)$ with temperature, i.e. to the case of "solid solution with variable composition", though the integral sorption properties of GO will not be changed significantly. For B-GO swelled in $\mathrm{CH}_{3} \mathrm{CN}$ (solid solvate) and in THF (solid solution) e.g. the same amount of solvent desorbs abruptly or gradually on heating from the melting point of the solvent to the ambient temperature, 0,36 and $0,33 \mathrm{~cm}^{3} \mathrm{~g}^{-1}$ respectively. Also the enthalpies of "abrupt desorption" (solid solvates) are close to the enthalpies of "gradual desorption" (solid solutions) (see Table 2S in Supplementary Material). For both types of temperature dependence equilibrium swelling/sorption reaches a maximum value at melting temperatures of the solvents. It is interesting also to discuss implications of our sorption results for dispersion of GO on single sheets usually achieved above ambient temperature using sonication. The inter-plane distances in GO above room temperatures are well below their maximal values. Clearly swelling/sorption is not the decisive factor for sonication induced dispersion of GO. No correlation was found between sorption properties (Table 1) and ability of the solvents to exfoliate GO, e.g. water, THF, NMP and DMF are successful solvents for exfoliation while methanol failed to provide stable dispersions of graphene oxide [6]. On the other hand significant increase of sorption/swelling with lowering temperature opens up possibilities to separate grapene oxide planes at temperatures well below ambient. First example of such delamination of $\mathrm{H}-\mathrm{GO}$ by sorption/swelling was given in ref. [27].

The equations similar to eq. $(1,2)$ can be obtained for the pressure dependence of $\mathrm{x}$ at constant temperature. If the solvent is $\mathrm{H}_{2} \mathrm{O}$ one gets 


$$
\frac{\left(V_{\mathrm{H}_{2} \mathrm{O}}^{G O}(p, x)-V_{\mathrm{H}_{2} \mathrm{O}, \mathrm{l}}(p)\right)}{\left(\frac{\partial \mu_{\mathrm{H}_{2} \mathrm{O}}^{G O}}{\partial x}\right)_{p}}=-\left(\frac{d x}{d p}\right)
$$

where $V_{\mathrm{H}_{2} \mathrm{O}}^{G \mathrm{O}}(p, x), V_{\mathrm{H}_{2} \mathrm{O}, \mathrm{l}}(p, x)$ are partial molar volumes of water at pressure $\mathrm{p}$ in $\mathrm{GO}$ at saturation ( $\mathrm{x}$ is a mass fraction of $\mathrm{H}_{2} \mathrm{O}$ at saturation) and in pure liquid water, respectively. (see Supplementary Material for details).

Non-monotonous pressure dependence of swelling was observed by XRD in the system B-GO $\mathrm{H}_{2} \mathrm{O}$ and $\mathrm{H}-\mathrm{GO}-\mathrm{H}_{2} \mathrm{O}$. Equation (3) accounts for the "maximum" of d for swelled $\mathrm{GO}$ at $\mathrm{T}=298$ $\mathrm{K}$ and $\mathrm{p}=1,2 \mathrm{GPa}$ [25]. This "maximum" occurs due to the change of phase in equilibrium with the swelled GO in the point of phase transition "liquid water-ice VI". The derivative in the right hand side changes sign from negative to positive if

$$
V_{\text {iceVI }}(p)<V_{\mathrm{H}_{2} \mathrm{O}}^{G O}(p, x)<V_{\mathrm{H}_{2} \mathrm{O}, \mathrm{l}}(p)
$$

According to ref. [37,38] partial molar volumes of ice VI and liquid water at $1.2 \mathrm{GPa}$ and ambient temperature are 13.7 and $14.4 \mathrm{~cm}^{3} / \mathrm{mol}$, respectively and the inequality (4) can be fulfilled.

\subsection{Water sorption isotherms for $\mathrm{H}-\mathrm{GO}$ and $\mathrm{H}-\mathrm{GOm}$}

Swelling properties of multilayered membranes prepared using vacuum filtration of graphene oxide dispersions were demonstrated earlier to be different compared to precursor graphite oxides [30]. However, only the lattice expansion was evaluated in this study by XRD. Here we provide quantitative estimation for the sorption of water by the membrane and graphite oxide powder samples. In agreement with XRD data the saturated sorption of water by $\mathrm{H}-\mathrm{GO}$ and $\mathrm{H}-$ GOm membrane were found to be different (Table 1). 
In order to gain some insight into this difference water sorption isotherms for $\mathrm{H}-\mathrm{GO}$ and $\mathrm{H}-\mathrm{GOm}$ membrane were measured at ambient temperature $(\mathrm{T}=298 \pm 5 \mathrm{~K})$ by ISP (see Table 2 ) and for $\mathrm{H}$ GO additionally by DDM method (see Figure 3).

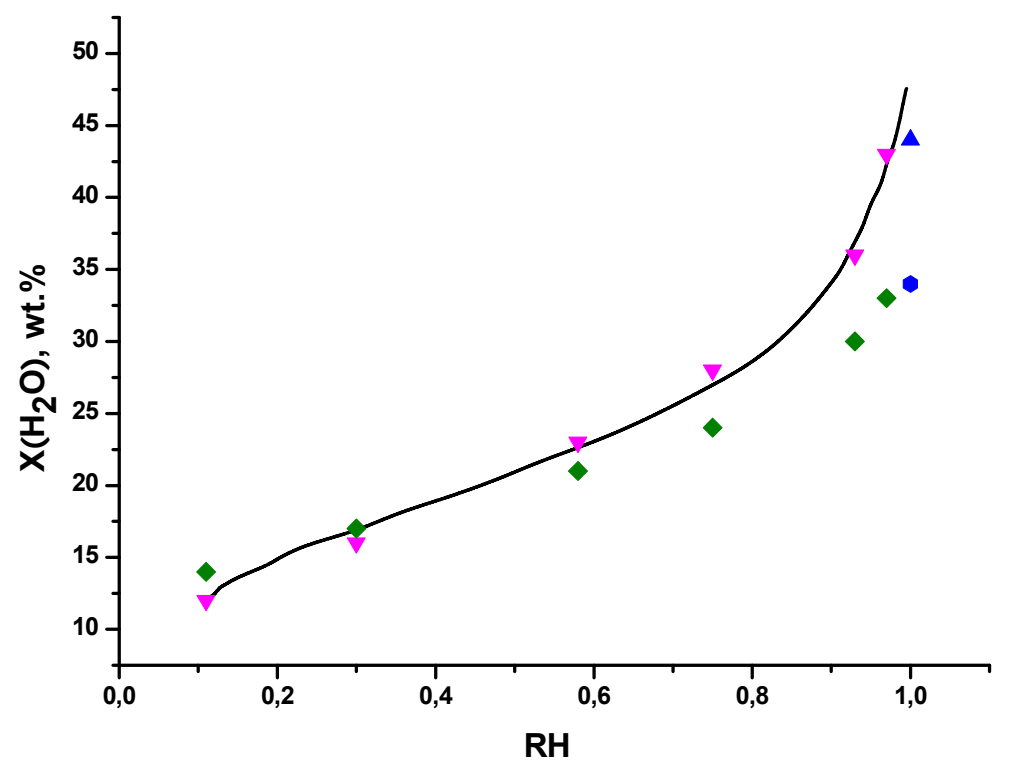

Figure 3. Sorption of $\mathrm{H}_{2} \mathrm{O}$ by $\mathrm{H}-\mathrm{GO}$ and $\mathrm{H}-\mathrm{GOm}$. T=298 $\pm 5 \mathrm{~K}$ K. Line - dynamic desorption isotherm for H-GO, Pink triangles( $\nabla$ ) - ISP data for H-GO, Green diamonds ( $\bullet$ ) - ISP data for H-GOm , blue triangle ( $\mathbf{\Delta}$ ) - DSC for H-GO, blue hexagon ( $)$ - DSC for H-GOm. DSC data are for $\mathrm{T}=273 \mathrm{~K}$.

The sorption/desorption data obtained for H-GO powder by ISP and DDM are in reasonable agreement. At high humidity $(0.9<\mathrm{RH}<1)$ the fraction of sorbed water goes up rapidly and doesn't reach saturation. The isotherm differs significantly from those for microporous activated carbons sorbing same amount of water [39] where such saturation is usually reached at $\mathrm{RH} \approx 0.8$, yet it's similar in appearance to typical isotherms for swelling polymers [31,40]. As it is seen from Table 2, the results obtained for $\mathrm{H}-\mathrm{GO}$ and $\mathrm{H}-\mathrm{GOm}$ membrane at $\mathrm{RH}<0.75$ coincide within the limits of experimental error. At RH close to unity the H-GO powder sorbed significantly 
more water compared to H-GOm membrane at room temperature according to ISP data and at $\mathrm{T}=273 \mathrm{~K}$ according to DSC measurements. XRD also showed higher inter-layer distances for saturated $\mathrm{H}-\mathrm{GO}$ compared to saturated $\mathrm{H}-\mathrm{GOm}$ at ambient temperature and at $\mathrm{T}=273 \mathrm{~K}$ [29]. As it was mentioned in ref. $[18,29] \mathrm{H}-\mathrm{GO}$ and $\mathrm{H}-\mathrm{GOm}$ are materials with different geometry of GO sheet edges and their overlaps. This difference in their structure may change sorption properties. One may also speculate that at $\mathrm{RH}>0,75$ additional specific fraction of water is sorbed by $\mathrm{H}-\mathrm{GO}$ [19-21,23]. This fraction is less pronounced in H-GOm.

Table 2. Mass fractions, $x$, of water $( \pm 3 \%)$ at different humidity. Isopiestic method. $T=298 \pm 5 \mathrm{~K}$.

\begin{tabular}{|c|c|c|}
\hline \multirow{2}{*}{ RH, p/p } & \multicolumn{2}{|c|}{$\mathrm{x}_{\mathrm{H} 2 \mathrm{O}}, \mathrm{wt}^{0} \%$} \\
& \multicolumn{2}{|c|}{$\left(\mathrm{cm}^{3}{ }_{\mathrm{H} 2 \mathrm{O}} / \mathrm{g}_{\mathrm{GO}}\right)$} \\
\cline { 2 - 3 } & $\mathrm{H}-\mathrm{GO}(3)^{1}$ & H-GOm membrane $(2)^{1}$ \\
\hline 0.11 & $12(0,14)^{2}$ & $14(0,16)$ \\
\hline 0.30 & $16(0,19)$ & $17(0,20)$ \\
\hline 0.58 & $23(0,29)$ & $21(0,27)$ \\
\hline 0.75 & $28(0,39)$ & $24(0,32)$ \\
\hline 0.93 & $36(0,56)$ & $30(0,43)$ \\
\hline 0.97 & $44(0,79)^{2}$ & $33(0,49)$ \\
\hline
\end{tabular}

${ }^{1}$ Number of samples studied, ${ }^{2}$ for $\mathrm{H}-\mathrm{GO}$ at $\mathrm{RH}=0.97$ seven samples were studied.

${ }^{2}$ Sorption in $\mathrm{cm}^{3}$ of $\mathrm{H}_{2} \mathrm{O}$ per gram of $\mathrm{H}-\mathrm{GO}$.

\subsection{H-GOm membranes water sorption properties vs permeation}

It is interesting to discuss relation between water sorption properties of GO membranes revealed here and water vapor permeation properties of GO membranes reported earlier. The data on 
permeation of water (r) through the $\mathrm{H}-\mathrm{GOm}$ membrane as a function of $\mathrm{RH}$ at ambient temperature reported by Nair et al. in ref. [12] and Supplementary Materials for ref.[12] can be correlated with amounts of water sorbed by H-GOm membrane determined in our experiments. Using volumetric sorption vs. humidity $(\mathrm{RH})$ dependence derived in our study for H-GOm membrane (Table 2) the permeation rates (r) measured in ref [12] can be plotted as a function of actual volume of water sorbed by the membrane at certain humidity levels (see Fig.4). The original r vs. RH dependence was strongly non-linear [12] while $r$ vs volumetric sorption ,v, demonstrates nearly linear behavior with R-factor equal to 0,967 (see Fig.4). It can be assumed that permeation rate is proportional to the amount of water sorbed by the membrane. For both $r$ and $v$ the reliable data were obtained at $\mathrm{RH}>0,15$.

The linear dependence of $r$ vs $v$ (Fig.4) can be explained by the simple quasi-equilibrium model. The scheme of vapor permeation method is shown in inset of Figure 4. One side of the membrane is exposed to feed water vapor and evaporation of water occurs on other side. Assuming feed side to be in sorption equilibrium, the sorption $v$ will be determined by RH within the sealed volume. The membrane operates in the stationary regime. The limiting step of permeation is a diffusion through the membrane as the opposite surface layer facing zero humidity conditions or vacuum $v^{\prime}=\mathrm{const}=0$. As a result the linear dependence of $r$ over $v$ is obtained.

It is instructive to estimate the effective diffusion coefficient, $\mathrm{D}$, from the simple diffusion formula

$$
r(R H)=D \frac{v(R H) \times \rho(H-G O)}{l}
$$

using the slope of $\mathrm{r}$ over $v$ linear dependence, $1 \sim 0,1 \mathrm{~cm}-$ effective diffusion length for $\sim 0.5 \mu \mathrm{m}$ thick H-GOm membrane according to estimation from ref [12] and $\rho \sim 1 \mathrm{~g} / \mathrm{cm}^{3}-$ density of H-GO swelled in water. The calculated value, $\mathrm{D}=(4,1 \pm 0,29) * 10^{-5} \mathrm{~cm}^{2} \mathrm{~s}^{-1}$ is in reasonable agreement 
with the self-diffusion coefficient of water in liquid $\left(\sim 2,3 * 10^{-5} \mathrm{~cm}^{2} \mathrm{~s}^{-1}\right)$ at ambient temperature [41].

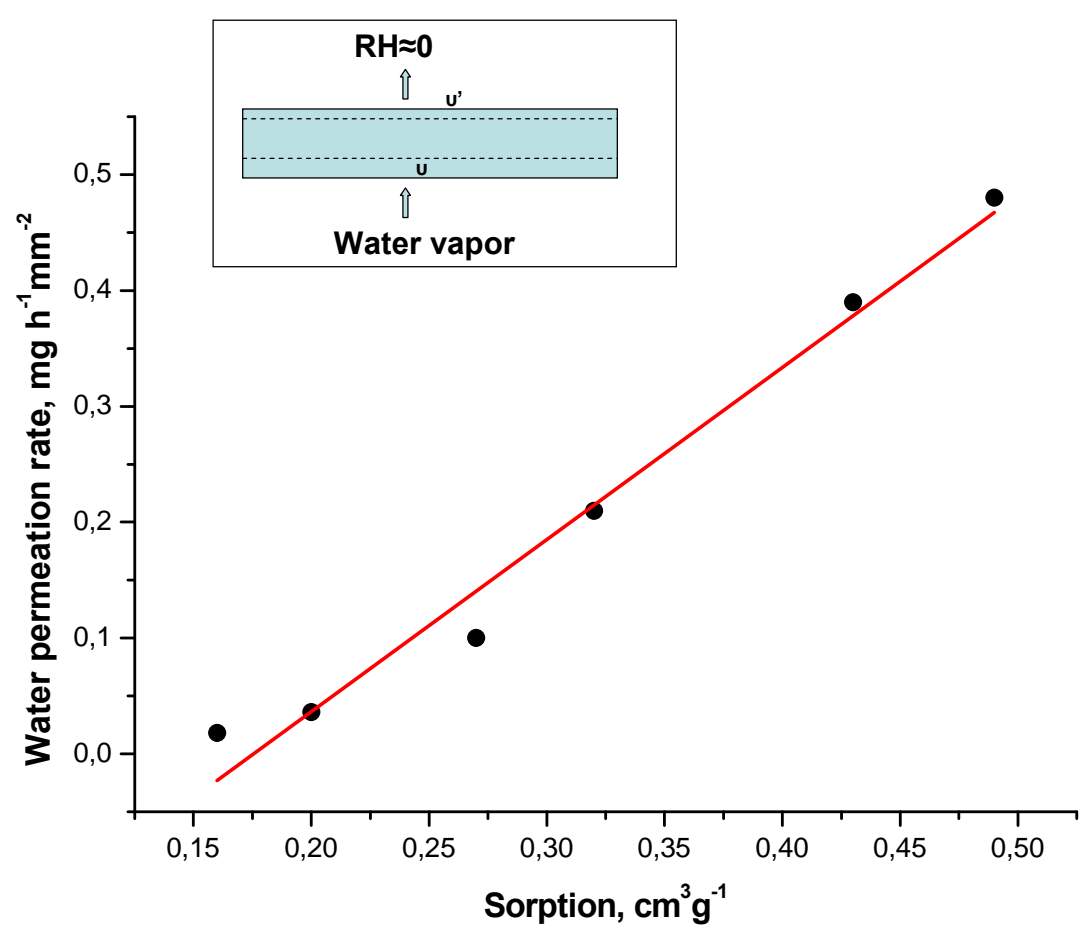

Figure 4. Water permeation rate through a $0.5-\mu \mathrm{m}$-thick GO membrane [12] vs volume sorption $v$, measured at the same RH (this work).

\section{Conclusions}

In summary, soprtion of B-GO and H-GO in several common liquid solvents was quantitatively estimated for ambient temperature and temperature points of solvent melting. The sorption of all studied solvents was found to be stronger for H-GO compared to B-GO and for all studied systems to be higher at lower temperature. The last-mentioned result opens up possibilities to separate graphene oxide sheets by swelling at temperatures below ambient. Sorption of all studied solvents by B-GO is remarkably similar if expressed in volumetric units $\left(\mathrm{cm}^{3} / \mathrm{g}\right)$ thus demonstrating that at equilibrium sorption into GO structure is controlled by limitations of available inter-layer volumes (lattice expansion) rather than by the number of available adsorption cites which would be the case if molar uptakes were similar. Sorption of water vapors 
was compared for $\mathrm{H}-\mathrm{GO}$ and multilayered membrane sample revealing certain difference at higher humidity levels.

Thermodynamic approach was used to account for $\mathrm{H}-\mathrm{GO}$ and B-GO sorption/swelling in polar organic solvents and water. This is a complex process sensitive to the way of material preparation and to the pre-history of the samples studied. Even if complete equilibrium in these systems is likely not achievable in our experiments, it was demonstrated that thermodynamic considerations can be used to describe characteristic temperature and pressure behavior of $\mathrm{GO} /$ solvent systems. The swelled materials were considered to be solid solvates of GOs and the two distinct types of their temperature behavior were explained within the concept of narrow or wide homogeneity ranges of the corresponding solvates. One and the same thermodynamic routine were used to account for temperature and pressure maximums of sorption/swelling at the points of phase transitions of the solvents. The equilibrium data on sorption were found useful in considering the rate of water permeation through the H-GOm membrane. Simple linear dependence of the permeation rate over sorption was estimated.

Clearly sorption/swelling of GO in our experimental conditions proceeds under thermodynamic rather than kinetic control. With more experimental data at hand we hope to extend this thermodynamic consideration into the sorption properties of different graphene oxide materials.

\section{Acknowlegments}

This work was supported by the RFBR grant 15-03-02168 and by the grant for Leading

Scientific Schools in Russia. A.T. acknowledges financial support from

Ångpanneforkningsstiftelse.

\section{AUTHOR INFORMATION}

Corresponding Author 
E-mail mkorobov49@gmail.com; Ph 7(495)6500468

\section{Notes}

The authors declare no competing financial interest.

\section{References}

[1] Dreyer DR, Park S, Bielawski CW, Ruoff RS. The chemistry of graphene oxide. Chem Soc Rev 2010; 39: 228-40.

[2] Zhu BY, Murali S, Cai W, Li X, Suk JW, Potts JR, et al. Graphene and graphene oxide: synthesis, properties and applications. Adv Mater 2010; 20: 1-19.

[3] Szabo T, Berkesi O, Forgo P, Josepovits K, Sanakis Y, Petridis D, et al. Evolution of Surface Functional Groups in a Series of Progressively Oxidized Graphite Oxides. Chemistry of Materials 2006; 18: 2740-49.

[4] Stankovich S, Dikin DA, Dommett GHB, Kohlhaas KM, Zimney EJ, Stach EA. et al. Graphene-based composite materials. Nature 2006; 442: 282-6.

[5] Stankovich S, Piner RD, Chen X, Wu N, Nguyen ST, Ruoff RS. Stable aqueous dispersions of graphitic nanoplatelets via the reduction of exfoliated graphite oxide in the presence of poly(sodium 4-styrenesulfonate). J Mater Chem 2006; 16: 155-8.

[6] Paredes JI, Villar-Rodil S, Martınez-Alonso A, Tascon JMD. Graphene oxide dispersions in organic solvents. Langmuir 2008; 24: 10560-4. 
[7] Kotov NA, Dekany I, Fendler JH. Ultrathin graphite oxide-polyelectrolyte composites prepared by self-assembly: Transition between conductive and non-conductive states. Adv Mater 1996; 8: 637-41.

[8] Eda G, Fanchini GM, Chhowalla M. Large-area ultrathin films of reduced graphene oxide as a transparent and flexible electronic material. Nature Nanotechnology 2008; 3: 270-4.

[9] Si Y, Samulski ET. Synthesis of Water Soluble Graphene. Nano Lett 2008; 8: 1679-82.

[10] Dikin DA, Stankovich S, Zimney EJ, Piner RD, Dommett GH, Evmenenko G, et al. Preparation and characterization of graphene oxide paper. Nature 2007; 448: 457-60.

[11] Chen CM, Yang QH, Yang YG, Lv W, Wen YF, Hou PX, et al. Self-Assembled Free-Standing Graphite Oxide Membrane. Adv Mater 2009; 21: 3007-11.

[12] Nair R, Wu HA, Jayaram PN, Grigorieva IV, Geim AK. Unimpeded permeation of water through helium-leak-tight graphene-based membranes. Science 2012; 335: 4424. Kim HW, Yoon HW, Yoon SM, Ahn BK, Cho YH, Shin SM, et al. Selective Gas Transport Through Few-Layered Graphene and Graphene Oxide Membranes. Science $2013 ; 342: 91-5$.

[14] Sun PZ, Zhu M, Wang KL, Zhong ML, Wei JQ, Wu DH, et al. Selective ion penetration of graphene oxide membranes. ACS Nano 2013; 7: 428-37. 

and Ultrafast Molecular Sieving Through Graphene Oxide Membranes. Science 2014; 343: 752-4. graphene oxide membranes for selective hydrogen separation. Science 2013; 342: 95-8. Kim D, Kim DW, Lim HK, Jeon J, Kim H, Jung HT, et al. Intercalation of gas molecules in graphene oxide interlayer: the role of water. J Phys Chem C 2014; 118 : $11142-8$. membranes in solvents and solutions. Nanoscale 2015; 7: 15374-84. behavior and dynamics of water molecules in graphite oxide. J Physics and Chemistry of Solids 2006; 67: 1106-10. with neutron scattering. J Phys Chem B 2006; 110: 22328-38. intercalated in graphite oxide. J Phys Chem C 2010; 114: 2604-12.

[22] Barroso-Bujans F, Cerveny S, Alegria A, Colmenero J. Sorption and desorption behavior of water and organic solvents from graphite oxide. Carbon 2010; 48: 3277-86. 
rotation and reorientation of water molecules in hydrated graphite oxide. Carbon 2013; 61: $367-72$.

Dependent Structural Breathing of Hydrated Graphite Oxide in $\mathrm{H}_{2} \mathrm{O}$. Carbon 2011; 49: 1894-99. et al. Colossal pressure-induced expansion of graphite oxide in the presence of water. Angew Chem Int Ed 2008; 47: 8268-71.

Oxide Solvates at Temperatures Near Ambient. J Phys Chem Lett 2012; 3: 812-7. MF, et al. Delamination of graphite oxide in a liquid upon cooling. Nanoscale 2015; 7: 12625-30.

[28] Szabo T, Berkesi O, Forgo P, Josepovits K, Sanakis Y, Petridis D, et al. Evolution of surface functional groups in a series of progressively oxidized graphite oxides. Chem Mater 2006; 18: 2740-9.

[29] You S, Luzan SM, Szabo T, Talyzin AV. Effect of Synthesis Method on Solvation and Exfoliation of Graphite Oxide. Carbon 2013; 52: 171-80. 

membranes in liquid water ethanol and water-ethanol mixtures. Nanoscale 2014; 6: 272 8.

[31] Gagarin AN, Tokmachev MG, Kovaleva SS, Ferapontov NB. The Properties of Water in Swollen Cross-Linked Polystyrene Sulfo Acids. Russian Journal of Physical Chemistry A 2008; 82: 1863-9. 2007: 704-24.

[33] Shkol'nikov EI, Volkov VV. Obtaining Vapor Desorption Isotherms without Monitoring Pressure. Doklady Physical Chemistry 2001; 378: 152-5.

[34] You S, Yu J, Sundqvist B, Belyaeva LA, Avramenko NV, Korobov MV, et al. Selective Intercalation of Graphite Oxide by Methanol in Water/Methanol Mixtures. J. Phys. Chem. C 2013; 117: 1963-8.

[35] CRC Handbook of Chemistry and Physics. 77th ed. Boca Raton FL: CRC Press; 1996.

[36] You S, Sundqvist B, Talyzin AV. Enormous Lattice Expansion of Hummers Graphite Oxide in Alcohols at Low Temperatures. ACS Nano 2013; 7: 1395-9.

[37] Kamb B. Structure of Ice VI. Science 1965; 150: 205-9. 

Floriano WB. Dielectric Constant and Density of Water as a Function of pressure at Constant Temperature. Brazilian Journal of Physics 2004; 34: 38-41.

[39] Alcan iz-Monge J, Linares-Solano A, Rand B. Water Adsorption on Activated Carbons: Study of Water Adsorption in Micro- and Mesopores. J Phys Chem B 2001; 105: 7998-8006.

[40] Shelkovnikova LA, Gavlina OT, Vitkina DE, Shkol'nikov EI, Ivanov VA. AcidBase Properties of Phenol Formaldehyde Sorbents. Russian Journal of Physical Chemistry A 2012; 86: 825-32.

[41] Krynicki K, Green CD, Sawyer DW. Pressure and temperature dependence of selfdiffusion in water. Faraday Discuss. Chem. Soc. 1978; 66: 199-208. 